ORIGINAL ARTICLE

\title{
GOLD classifications and mortality in chronic obstructive pulmonary disease: the HUNT Study, Norway
}

\author{
Linda Leivseth, ${ }^{1}$ Ben Michael Brumpton, ${ }^{1}$ Tom Ivar Lund Nilsen, ${ }^{2}$ Xiao-Mei Mai, ${ }^{1}$ \\ Roar Johnsen, ${ }^{1}$ Arnulf Langhammer ${ }^{3}$
}

\begin{abstract}
- Additional material is published online only. To view please visit the journal online (http://dx.doi.org/10.1136/ thoraxjnl-2013-203270).

1 Department of Public Health and General Practice, Norwegian University of Science and Technology (NTNU), Trondheim, Norway ${ }^{2}$ Department of Human Movement Science, Norwegian University of Science and Technology (NTNU), Trondheim, Norway ${ }^{3}$ Department of Public Health and General Practice, HUNT Research Centre, Norwegian University of Science and Technology (NTNU), Levanger, Norway
\end{abstract}

Correspondence to Linda Leivseth, Department of Public Health and General Practice, Norwegian University of Science and Technology (NTNU), Postbox 8905, MTFS, N0-7491 Trondheim, Norway; linda.leivseth@ntnu.no

Received 16 January 2013 Revised 19 March 2013 Accepted 27 March 2013 Published Online First 23 April 2013

\section{SLinked}

http://dx.doi.org/10.1136 thoraxjnl-2013-203595

To cite: Leivseth $\mathrm{L}$, Brumpton BM, Nilsen TIL, et al. Thorax 2013;68: 914-921.

\section{ABSTRACT}

Background How different Global Initiative for Chronic Obstructive Lung Disease (GOLD) classifications of chronic obstructive pulmonary disease (COPD) predict mortality is unclear.

Objective To examine the association of spirometric GOLD grades and the new ABCD groups with mortality, and to compare their informativeness in relation to mortality.

Methods We studied 1540 people with postbronchodilator COPD who participated in the Norwegian Nord-Trøndelag Health Study 1995-1997 and were followed up on all-cause mortality until May 2012. The associations of spirometric GOLD grades and $A B C D$ groups with mortality were estimated by sex specific adjusted HRs from Cox regression and standardised mortality ratios. To assess the informativeness of spirometric GOLD grades and ABCD groups at predicting mortality we used the difference in twice the loglikelihood of a Cox regression model with and without each COPD classification.

Results The distribution of participants was $28 \%$ in GOLD 1, $57 \%$ in GOLD 2, $13 \%$ in GOLD 3 and 2\% in GOLD 4, in contrast to $61 \%$ in group $A, 18 \%$ in group $\mathrm{B}, 12 \%$ in group $\mathrm{C}$ and $10 \%$ in group $\mathrm{D}$. During a median of 14.6 years of follow-up, 837 people (54\%) died. Mortality increased gradually from GOLD 1 to 4 , while it was generally similar in groups $A$ and $B$, and in groups $C$ and D. Spirometric GOLD grades were substantially more informative than $A B C D$ groups at predicting mortality.

Conclusions Spirometric GOLD grades predicted mortality better than the new $A B C D$ groups among people with COPD from a Norwegian general population.

\section{INTRODUCTION}

Chronic obstructive pulmonary disease (COPD) is a major cause of morbidity and mortality worldwide ${ }^{1}$ and it is estimated to be the fourth leading cause of death by $2030 .^{2}$ According to the Global Initiative for Chronic Obstructive Lung Disease (GOLD), a diagnosis of COPD should be based on postbronchodilator spirometric measurements, and the severity should be graded based on per cent predicted forced expiratory volume in $1 \mathrm{~s}$ $\left(\mathrm{ppFEV}_{1}\right) .^{34}$

However, the 2011 revision of the GOLD strategy document presented a new $\mathrm{ABCD}$ group classification of COPD which intended to provide a better

\section{Key messages}

What is the key question?

- Which of the spirometric Global Initiative for Chronic Obstructive Lung Disease (GOLD) grades or the new $A B C D$ groups is the better predictor of mortality in chronic obstructive pulmonary disease (COPD)?

What is the bottom line?

- Spirometric GOLD grades predicted mortality better than the new $A B C D$ groups.

Why read on?

- This is the first population-based study evaluating which of the spirometric GOLD grades or the new $A B C D$ groups is the better predictor of mortality in people with COPD.

understanding of the impact of the disease on an individual patient than spirometric GOLD grades. ${ }^{3} 4$ The $\mathrm{ABCD}$ groups combine symptom burden and risk of exacerbations, where the latter is estimated from the spirometric GOLD grades and the number of exacerbations in the last year. ${ }^{3}{ }^{4}$ The association of spirometric GOLD grades and ABCD groups with mortality has been examined in two recent studies. ${ }^{5} 6$ In the first study, both pre-bronchodilator spirometric GOLD grades and ABCD groups predicted mortality in a general population in Denmark, but which measure best predicted mortality was not formally tested. $^{5}$ In this Danish study, survival was poorer in people with relatively high lung function and dyspnoea compared with people with lower lung function without dyspnoea. ${ }^{5}$ In the second study, pooled data from 11 Spanish COPD cohorts showed no difference between post-bronchodilator spirometric GOLD grades and ABCD groups in predicting mortality. ${ }^{6}$

We aimed to examine the association of spirometric GOLD grades and the new ABCD groups with mortality, and to compare their informativeness in relation to mortality.

\section{METHODS}

\section{Study population}

From August 1995 to June 1997, all residents in Nord-Trøndelag County in Norway aged 19 years or older were invited to participate in the second wave of the Nord-Trøndelag Health Study (HUNT2). ${ }^{7}$ Among 
Figure 1 Flow chart of inclusion and exclusion in the HUNT2 Lung Study.

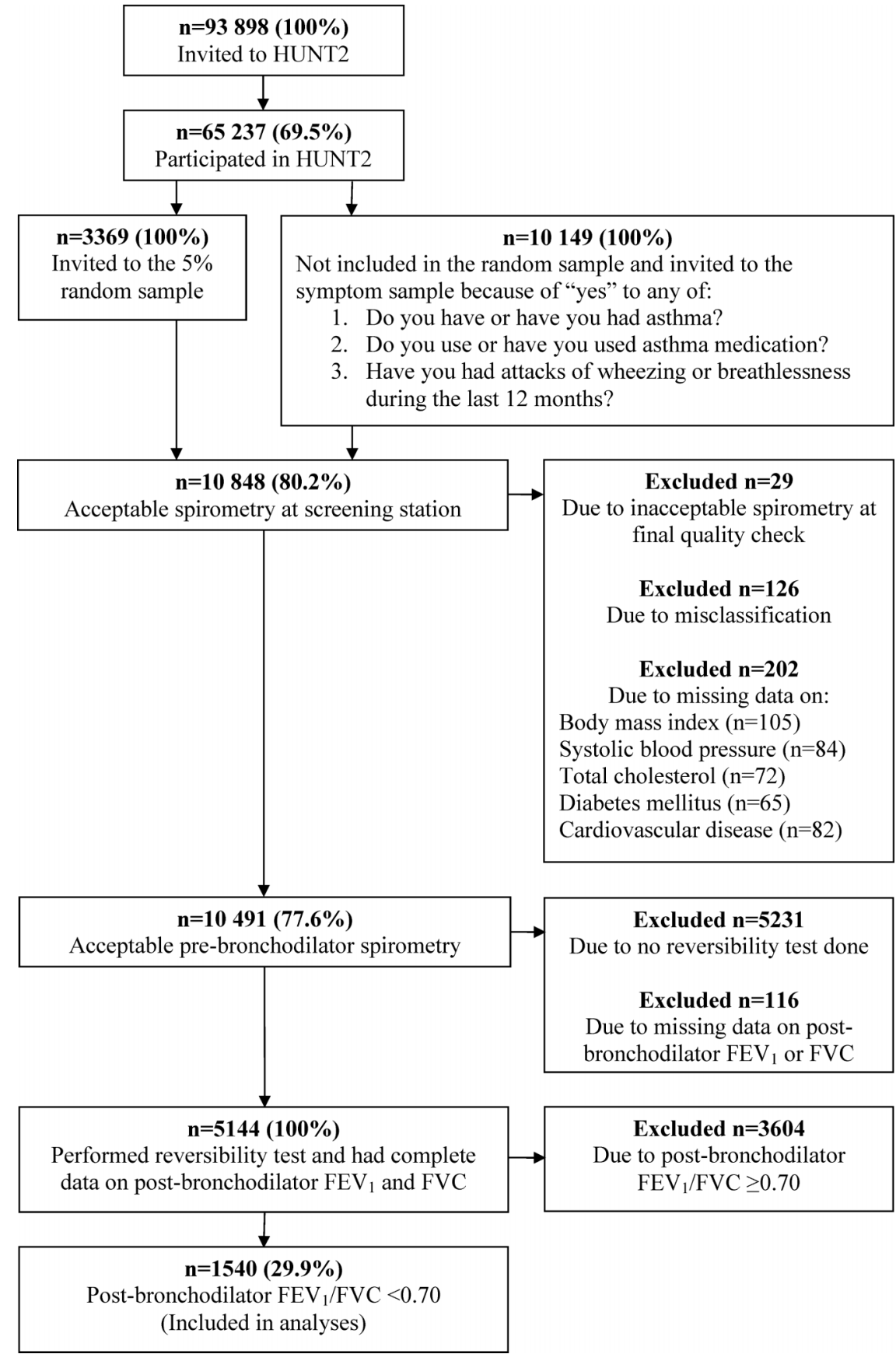

the 65237 participants (69.5\% of those invited), a 5\% random sample and a symptom sample were invited to participate in the Lung Study. ${ }^{8}$ Briefly, the symptom sample included participants reporting attacks of wheezing or breathlessness during the last 12 months, having ever had asthma and/or having ever used asthma medication, and who were not included in the random sample. As described elsewhere, ${ }^{10}$ a $\beta_{2}$-agonist reversibility test was performed on a subsample of the 10491 Lung Study participants with acceptable pre-bronchodilator spirometry. Among 5144 participants with complete data on post-bronchodilator $\mathrm{FEV}_{1}$ and forced vital capacity (FVC), the 1540 participants with post-bronchodilator $\mathrm{FEV}_{1}$ / FVC $<0.70$ comprised the study cohort (figure 1 ).

\section{Study variables}

At participation in HUNT2, questionnaire information was collected on a range of lifestyle and health related factors, and all participants underwent a clinical examination. ${ }^{7}$ The Lung Study participants completed an additional lung specific questionnaire, an interview and flow volume spirometry. ${ }^{9}$

Lung function and spirometric GOLD grades

Flow volume spirometry was recorded according to the 1994 American Thoracic Society recommendations ${ }^{11}$ as described elsewhere. ${ }^{9}$ Spirometry was performed before and $30 \mathrm{~min}$ after inhalation of $1 \mathrm{mg}$ terbutaline. ${ }^{10}$ Pre- and post-bronchodilator $\mathrm{FEV}_{1}$ and FVC were obtained, and the prediction equations of Langhammer et $a l^{9}$ were used to calculate $\operatorname{ppFEV}_{1}$. Post-bronchodilator $\mathrm{FEV}_{1} / \mathrm{FVC}<0.70$ defined COPD, and airflow limitation was graded according to GOLD criteria as GOLD 1 $\left(\mathrm{ppFEV}_{1} \geq 80\right)$, GOLD $2\left(50 \leq \mathrm{ppFEV}_{1}<80\right)$, GOLD $3(30 \leq$ $\left.\operatorname{ppFEV}_{1}<50\right)$ and GOLD $4\left(\mathrm{ppFEV}_{1}<30\right)$. $^{34}$ 


\section{$A B C D$ groups}

We generated $\mathrm{ABCD}$ groups based on symptom burden and exacerbation risk according to the 2011 GOLD strategy document. ${ }^{3}{ }^{4}$ According to GOLD, ${ }^{3}{ }^{4}$ symptom burden should be measured by the modified Medical Research Council (mMRC) dyspnoea scale ${ }^{12}$ or the COPD Assessment Test (CAT),${ }^{13}$ and exacerbation risk by the GOLD grades of airflow limitation or exacerbation history. The ABCD group classification is based on a $2 \times 2$ table with cells labelled A, B, C and D. Symptom burden is divided into low (A and $\mathrm{C}$ ) and high ( $\mathrm{B}$ and $\mathrm{D}$ ), whereas airflow limitation and/or exacerbation history separates A from $\mathrm{C}$, and B from D. Regarding the latter, patients should be placed in the group that gives the highest exacerbation risk according to airflow limitation $\left(\mathrm{ppFEV}_{1}<50\right)$ or exacerbation history $(\geq 2$ last year). ${ }^{3}{ }^{4}$ In the current study, symptom burden was measured by a dyspnoea scale included in the lung specific questionnaire (22\% missing data). ${ }^{8}{ }^{14} 15$ We used a cut-off on 'Do you become short of breath when walking on flat ground at a normal pace?' which approximates to dyspnoea grade 2 according to the mMRC dyspnoea scale. ${ }^{12}$ Airflow limitation was graded as described above. Exacerbation history $(\leq 1, \geq 2$ last year) was generated from two questions; 'Have you ever taken cortisone tablets for breathing problems/asthma?' and 'How many cortisone courses have you taken in the last year?' Among participants with data on the dyspnoea scale, four people $(0.2 \%)$ had missing data on exacerbation history, and these were placed in an exacerbation risk group based on their spirometric GOLD grade.

\section{Follow-up}

The study cohort was followed from the date of attendance in HUNT2 to the date of death or emigration, or the end of follow-up, 24 May 2012, whichever came first. There were no other losses to follow-up. The outcome was all-cause mortality, and date of death was obtained from the Cause of Death Registry in Norway.

\section{Statistical analyses}

Baseline characteristics were presented according to spirometric GOLD grades and ABCD groups. Most statistical analyses were sex specific because women and men differ in many ways including hormonal and immunological determinants, ${ }^{16}$ perception and reporting of symptoms, ${ }^{16}{ }^{17}$ and exposure to cigarette smoke or other noxious particles and gasses. ${ }^{4}$ Death rates per 1000 person-years were calculated for spirometric GOLD grades and ABCD groups. We also calculated standardised mortality ratios (SMRs) with 95\% CIs using the Norwegian population death rates as reference. ${ }^{18}$ These death rates were presented separately for women and men, 5 -year age bands $(20-24, \ldots$, $85-89, \geq 90)$, and 5-year calendar periods $(1991-1995, \ldots$, 2006-2010, 2011). By sorting our data in the same way we calculated the expected number of deaths within spirometric GOLD grades and ABCD groups in our study cohort. SMRs were obtained when comparing the observed to the expected number of deaths. Unadjusted Kaplan-Meier curves with time of follow-up as the time scale were generated in order to visualise mortality trends according to spirometric GOLD grades and $\mathrm{ABCD}$ groups.

Cox proportional hazard regression was used to compute HRs with 95\% CIs for the association of spirometric GOLD grades and $\mathrm{ABCD}$ groups with mortality. All associations were adjusted for potential confounding by age (as the time scale), ${ }^{19}$ smoking (current, former, never, unknown (4.5\%)), and education $(<10, \geq 10$ years, unknown $(8.7 \%))$ as identified through directed acyclic graphs. ${ }^{20}{ }^{21}$ In separate models we also assessed possible confounding by body mass index (BMI) $\left(<18.5,18.5-24.9,25.0-29.9, \geq 30.0 \mathrm{~kg} / \mathrm{m}^{2}\right)$, physical activity (inactive, light activity $<1 \mathrm{~h} /$ week, light activity $1-2 \mathrm{~h} /$ week, light activity $\geq 3 \mathrm{~h} /$ week, only vigorous activity, unknown (3.1\%)), cardiovascular disease (CVD) (yes, no), diabetes mellitus (DM) (yes, no), total cholesterol (sex specific quartiles; $\mathrm{mmol} / \mathrm{l}$ ), and systolic blood pressure (SBP) (sex specific quartiles; $\mathrm{mm} \mathrm{Hg}$ ). Departures from the proportional hazard assumptions were evaluated by inspecting log-log survival curves for each covariate, calculating Schoenfeld residuals and producing formal tests of interaction with time or log time.

To study how well spirometric GOLD grades and ABCD groups predicted mortality, we estimated their informativeness according to the method described by Peto et $a l^{22}$ and later used by others. ${ }^{23-25}$ The informativeness was computed as the difference in twice the log-likelihood between a Cox proportional hazard null model (including age as the time scale, smoking and education) and an alternative model (including spirometric GOLD grades or ABCD groups in addition to all in the null model). This difference approximately follows a $\chi^{2}$ distribution. The greater the difference, the more informative is that particular predictor. To help compare models, we set the most informative model to $100 \%$ and compared the other model with this reference. Additionally, we analysed the area under the receiver operating characteristic curve (AUC) and the pseudo $\mathrm{R}^{2}$ from logistic regression models including the same variables as presented above.

In subsequent sensitivity analyses we generated $\mathrm{ABCD}$ groups with three alternate measures of symptom burden. First, 'Have you had any kind of attack of wheezing or breathlessness during the last 12 months?' (no missing data). Second, 'Have you at any time in the last 12 months been short of breath when resting during the day?' $(0.2 \%$ missing data). 'No' was regarded as low and 'yes' as high symptom burden. Third, 'How is your health at the moment?' ( $0.8 \%$ missing data). 'Good/very good' were regarded as low and 'poor/not so good' as high symptom burden.

Statistical analyses were conducted using Stata V.12.1. All statistical tests were two-sided.

\section{Ethics}

The Regional Committee for Medical Research Ethics (reference 4.2008.59) approved the study, and the Norwegian Data Inspectorate licensed the research register (reference 06/ 00104-39/CGN). All participants signed informed written consents.

\section{RESULTS}

\section{Baseline characteristics and distribution of participants}

In this prospective cohort study of 1540 people with COPD, 837 people $(54 \%)$ died during a median of 14.6 years (18 150 person-years) of follow-up. Baseline characteristics are presented in table 1 . When classified by spirometric GOLD grade, the distribution of participants was $28 \%$ in GOLD 1, $57 \%$ in GOLD 2, $13 \%$ in GOLD 3 and 2\% in GOLD 4. In contrast, when classified by $A B C D$ group, the distribution of participants was $61 \%$ in group A, $18 \%$ in group B, $12 \%$ in group C and $10 \%$ in group D.

\section{Spirometric GOLD grades and ABCD groups in association with mortality}

Compared to GOLD 1 or the general population, mortality increased with higher spirometric GOLD grade (table 2). 
Table 1 Baseline characteristics according to spirometric Global Initiative for Chronic Obstructive Lung Disease (GOLD) grades* and ABCD groupst among participants with chronic obstructive pulmonary disease (COPD) in the HUNT2 Lung Study

\begin{tabular}{|c|c|c|c|c|c|c|c|}
\hline & $\begin{array}{l}\text { Participants } \\
\text { n (\%)‡ }\end{array}$ & $\begin{array}{l}\text { Ever } \\
\text { smokers } \\
\text { n (\%)§ }\end{array}$ & $\begin{array}{l}\text { Education } \\
\geq 10 \text { years } \\
n(\%) \S\end{array}$ & $\begin{array}{l}\text { Inactive } \\
\text { n (\%)§ }\end{array}$ & $\begin{array}{l}\text { Cardiovascular } \\
\text { disease } \\
\text { n (\%)§ }\end{array}$ & $\begin{array}{l}\text { Body mass } \\
\text { index }\left(\mathrm{kg} / \mathrm{m}^{2}\right) \\
\text { Mean }(\mathrm{SD})\end{array}$ & $\begin{array}{l}\text { Age (years) } \\
\text { Mean (SD) }\end{array}$ \\
\hline \multicolumn{8}{|l|}{ Women } \\
\hline \multicolumn{8}{|c|}{ GOLD grades $(n=584)$} \\
\hline GOLD 1 & $173(29.6)$ & $95(58.6)$ & $51(32.1)$ & $19(12.9)$ & $21(12.1)$ & $26.7(4.7)$ & $62.4(15.9)$ \\
\hline GOLD 2 & $338(57.9)$ & $240(75.0)$ & $98(32.1)$ & $43(16.8)$ & $46(13.6)$ & $27.1(5.6)$ & $61.7(12.0)$ \\
\hline GOLD 3 & $64(11.0)$ & 49 (83.1) & $12(23.5)$ & $6(17.6)$ & $10(15.6)$ & $24.3(4.4)$ & $63.7(10.2)$ \\
\hline GOLD 4 & $9(1.5)$ & $6(85.7)$ & $3(37.5)$ & $3(42.9)$ & 1 (11.1) & $23.5(2.7)$ & $59.6(8.9)$ \\
\hline \multicolumn{8}{|c|}{$A B C D$ groups $(n=468)$} \\
\hline Group A & $278(59.4)$ & $179(69.4)$ & $90(35.3)$ & $24(10.8)$ & $31(11.2)$ & $26.3(5.0)$ & $61.9(13.9)$ \\
\hline Group B & $100(21.4)$ & 75 (77.3) & $25(26.3)$ & $19(24.4)$ & $13(13.0)$ & $29.1(6.1)$ & $62.3(12.2)$ \\
\hline Group C & $42(9.0)$ & $26(63.4)$ & $10(28.6)$ & $1(3.7)$ & $8(19.0)$ & $24.3(3.7)$ & $63.4(11.3)$ \\
\hline Group D & $48(10.3)$ & $33(78.6)$ & $11(28.2)$ & $6(20.0)$ & $7(14.6)$ & $27.0(5.0)$ & $64.6(9.7)$ \\
\hline \multicolumn{8}{|l|}{ Men } \\
\hline \multicolumn{8}{|c|}{ GOLD grades $(n=956)$} \\
\hline GOLD 1 & $251(26.3)$ & $197(83.1)$ & $117(50.0)$ & $17(7.8)$ & $44(17.5)$ & $26.6(3.6)$ & $61.6(13.6)$ \\
\hline GOLD 2 & $545(57.0)$ & $471(89.0)$ & $216(44.3)$ & $56(12.4)$ & $136(25.0)$ & $26.5(3.8)$ & $64.5(12.5)$ \\
\hline GOLD 3 & $140(14.6)$ & $124(94.7)$ & $36(28.8)$ & $17(15.6)$ & $27(19.3)$ & $25.1(3.8)$ & $69.6(9.5)$ \\
\hline GOLD 4 & $20(2.1)$ & $20(100.0)$ & $4(23.5)$ & $4(26.7)$ & $4(20.0)$ & $23.9(2.8)$ & $67.7(7.9)$ \\
\hline \multicolumn{8}{|c|}{$A B C D$ groups $(n=736)$} \\
\hline Group A & $453(61.6)$ & $371(85.5)$ & $207(49.5)$ & $29(7.5)$ & $80(17.7)$ & $26.2(3.5)$ & $62.8(12.9)$ \\
\hline Group B & $116(15.8)$ & 109 (95.6) & $41(40.2)$ & $17(18.3)$ & $41(35.3)$ & $28.0(4.4)$ & $66.2(11.7)$ \\
\hline Group C & 100 (13.6) & $81(86.2)$ & $38(40.4)$ & $12(15.2)$ & $16(16.0)$ & $25.2(3.3)$ & $67.5(11.0)$ \\
\hline Group D & $67(9.1)$ & $61(93.8)$ & $18(32.7)$ & $13(24.5)$ & $15(22.4)$ & $25.3(4.2)$ & $69.3(9.5)$ \\
\hline
\end{tabular}

Compared to group $\mathrm{A}$, women in groups $\mathrm{C}$ and $\mathrm{D}$ and men in group D had increased mortality. Compared to the general population, women and men in most ABCD groups had increased mortality. In general, mortality did not differ substantially between groups $\mathrm{A}$ and $\mathrm{B}$, and between groups $\mathrm{C}$ and D. Further adjustments for BMI, physical activity, CVD, DM, total cholesterol and SBP did not materially change the estimates (data not shown). The sensitivity analyses with alternate measures of dyspnoea or health status supported our main findings (see online supplementary table S1 for women and online supplementary table S2 for men).

The unadjusted Kaplan-Meier curves demonstrated large differences in survival between the four spirometric GOLD grades among women and men (figure 2). Among women, there were small differences in survival between groups $\mathrm{A}$ and $\mathrm{B}$, and between groups $\mathrm{C}$ and $\mathrm{D}$ (figure 3 ). In contrast, survival was lower among men in group B compared to A, and in group D compared to $\mathrm{C}$ (figure 3 ).

\section{Informativeness}

Spirometric GOLD grades were more informative than ABCD groups at predicting mortality (table 3 ). These findings were supported by the additional analyses of AUC and pseudo $\mathrm{R}^{2}$ (see online supplementary table S3) and the sensitivity analyses with alternate measures of dyspnoea or health status (see online supplementary tables S4 and S5).

\section{DISCUSSION}

Among participants with COPD in the Norwegian HUNT2 Lung Study, spirometric GOLD grades predicted mortality better than $A B C D$ groups. Mortality increased gradually from GOLD 1 to 4 , while it was similar in group A compared to B, and in group $\mathrm{C}$ compared to $\mathrm{D}$.

\section{Spirometric GOLD grades and $A B C D$ groups in association with mortality}

In accordance with other epidemiological studies, ${ }^{56-28}$ mortality increased with higher spirometric GOLD grade in the current study. In general, our study showed similar mortality in groups $\mathrm{A}$ and $\mathrm{B}$, and in groups $\mathrm{C}$ and $\mathrm{D}$, which may indicate that symptom burden does not influence mortality substantially. In support of this, we observed that the choice of symptom burden instrument did not affect our findings. The unadjusted KaplanMeier curves indicated that reporting dyspnoea when walking might be associated with lower survival in men but not in women. However, these curves must be interpreted with caution since possible confounders like age, smoking and education were more unfavourable among people in group B compared to A, and in group $\mathrm{D}$ compared to $\mathrm{C}$.

A likely explanation of the small differences in mortality between groups $\mathrm{A}$ and $\mathrm{B}$, and between groups $\mathrm{C}$ and $\mathrm{D}$, may be that $\mathrm{ppFEV}_{1}$ is dichotomised at 50 in the $\mathrm{ABCD}$ classification, resulting in less discrimination between people with different lung function. Hence, symptom burden may still be associated 
Table 2 Death rates, adjusted HRs, and standardised mortality ratios (SMRs) with 95\% Cls for the associations of spirometric Global Initiative for Chronic Obstructive Lung Disease (GOLD) grades and $A B C D$ groups with all-cause mortality among participants with chronic obstructive pulmonary disease (COPD) in the HUNT2 Lung Study

\begin{tabular}{|c|c|c|c|c|c|c|c|c|c|c|}
\hline COPD classification & Person-years & Observed deaths & Death rate* & $(95 \% \mathrm{Cl})$ & Age-adjusted HRT & Multi-adjusted HR & $(95 \% \mathrm{Cl}) \neq$ & Expected deaths & SMR§ & $(95 \% \mathrm{Cl}) \S$ \\
\hline \multicolumn{11}{|l|}{ Women } \\
\hline GOLD grades $\uparrow(n=584)$ & 7393 & 273 & 36.93 & (32.80 to 41.58 ) & & & & & & \\
\hline GOLD 1 & 2366 & 59 & 24.94 & (19.32 to 32.19$)$ & 1.00 & 1.00 & (Reference) & 79 & 0.75 & (0.59 to 0.95$)$ \\
\hline GOLD 2 & 4341 & 155 & 35.70 & (30.50 to 41.79 ) & 2.32 & 2.29 & (1.66 to 3.16$)$ & 91 & 1.70 & (1.46 to 1.99$)$ \\
\hline GOLD 3 & 583 & 52 & 89.12 & (67.91 to 116.96 ) & 6.48 & 6.23 & (4.15 to 9.36 ) & 11 & 4.72 & (3.62 to 6.08 ) \\
\hline GOLD 4 & 102 & 7 & 68.55 & (32.68 to 143.78 ) & 6.90 & 6.97 & (3.05 to 15.91 ) & 1 & 5.15 & (2.45 to 9.92 ) \\
\hline ABCD groups ${ }^{* *}(n=468)$ & 5918 & 217 & 36.67 & (32.10 to 41.89 ) & & & & & & \\
\hline Group A & 3667 & 115 & 31.36 & (26.12 to 37.65 ) & 1.00 & 1.00 & (Reference) & 96 & 1.19 & (0.99 to 1.44 ) \\
\hline Group B & 1268 & 42 & 33.12 & (24.47 to 44.81 ) & 1.22 & 1.12 & (0.78 to 1.62$)$ & 27 & 1.56 & (1.18 to 2.08 ) \\
\hline Group C & 453 & 28 & 61.85 & (42.70 to 89.58 ) & 2.08 & 2.47 & (1.62 to 3.79 ) & 11 & 2.55 & (1.62 to 3.94$)$ \\
\hline Group D & 530 & 32 & 60.41 & (42.72 to 85.42 ) & 2.14 & 2.43 & (1.62 to 3.66$)$ & 12 & 2.62 & (1.77 to 3.82 ) \\
\hline \multicolumn{11}{|l|}{ Men } \\
\hline GOLD grades $\uparrow(\mathrm{n}=956)$ & 10757 & 564 & 52.43 & (48.28 to 56.94 ) & & & & & & \\
\hline GOLD 1 & 3259 & 108 & 33.14 & (27.44 to 40.02 ) & 1.00 & 1.00 & (Reference) & 119 & 0.91 & (0.76 to 1.08$)$ \\
\hline GOLD 2 & 6142 & 327 & 53.24 & (47.77 to 59.34 ) & 1.51 & 1.44 & (1.15 to 1.80$)$ & 246 & 1.33 & (1.20 to 1.47 ) \\
\hline GOLD 3 & 1189 & 110 & 92.51 & (76.74 to 111.51 ) & 2.03 & 2.04 & (1.56 to 2.68 ) & 62 & 1.77 & (1.47 to 2.12 ) \\
\hline GOLD 4 & 167 & 19 & 113.58 & (72.45 to 178.07 ) & 4.28 & 4.24 & (2.57 to 7.00 ) & 5 & 3.47 & (2.70 to 4.39 ) \\
\hline$A B C D$ groups ${ }^{* *}(n=736)$ & 8350 & 436 & 52.22 & (47.54 to 57.36 ) & & & & & & \\
\hline Group A & 5437 & 242 & 44.51 & (39.24 to 50.49 ) & 1.00 & 1.00 & (Reference) & 196 & 1.24 & (1.10 to 1.39 ) \\
\hline Group B & 1310 & 72 & 54.97 & (43.63 to 69.25 ) & 0.97 & 0.89 & (0.68 to 1.16$)$ & 61 & 1.18 & (0.95 to 1.47 ) \\
\hline Group C & 1041 & 69 & 66.27 & (52.34 to 83.90 ) & 1.08 & 1.10 & (0.84 to 1.44$)$ & 52 & 1.32 & (1.04 to 1.68 ) \\
\hline Group D & 562 & 53 & 94.38 & (72.10 to 123.53 ) & 1.63 & 1.70 & (1.25 to 2.29 ) & 27 & 1.98 & (1.50 to 2.59$)$ \\
\hline
\end{tabular}

\section{*Per 1000 person-years.}

tAdjusted for age (as the time scale).

$\neq$ Adjusted for age (as the time scale), smoking (never, former, current, unknown) and education $(<10, \geq 10$ years, unknown).

$\S$ Standardised according to sex, 5-year age bands and 5-year calendar periods.

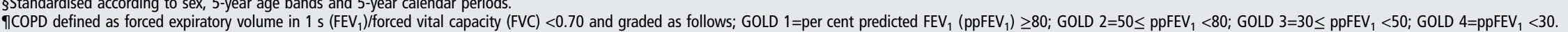

${ }_{*}^{*} A B C D$ groups defined as follows; $A=$ dyspnoea $\leq$ grade 1 , GOLD 1 or 2 , and $\leq 1$ exacerbation last 12 months; $B=$ dyspnoea $\geq$ grade 2 , GOLD 1 or 2 , and $\leq 1$ exacerbation last 12 months; $C=$ dyspnoea $\leq$ grade 1 , and GOLD 3 or 4 or $\geq 2$ exacerbations last 12 months; $D=$ dyspnoea $\geq$ grade 2 , and GOLD 3 or 4 or $\geq 2$ exacerbations last 12 months. 

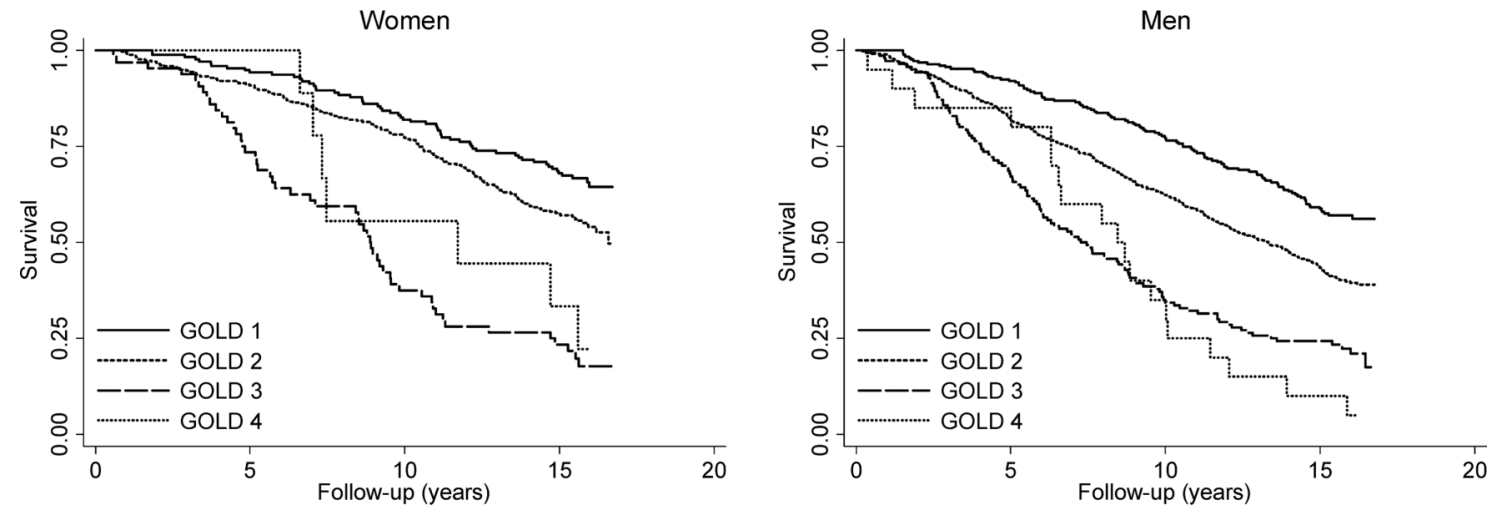

Figure 2 Kaplan-Meier curves according to spirometric Global Initiative for Chronic Obstructive Lung Disease (GOLD) grades.
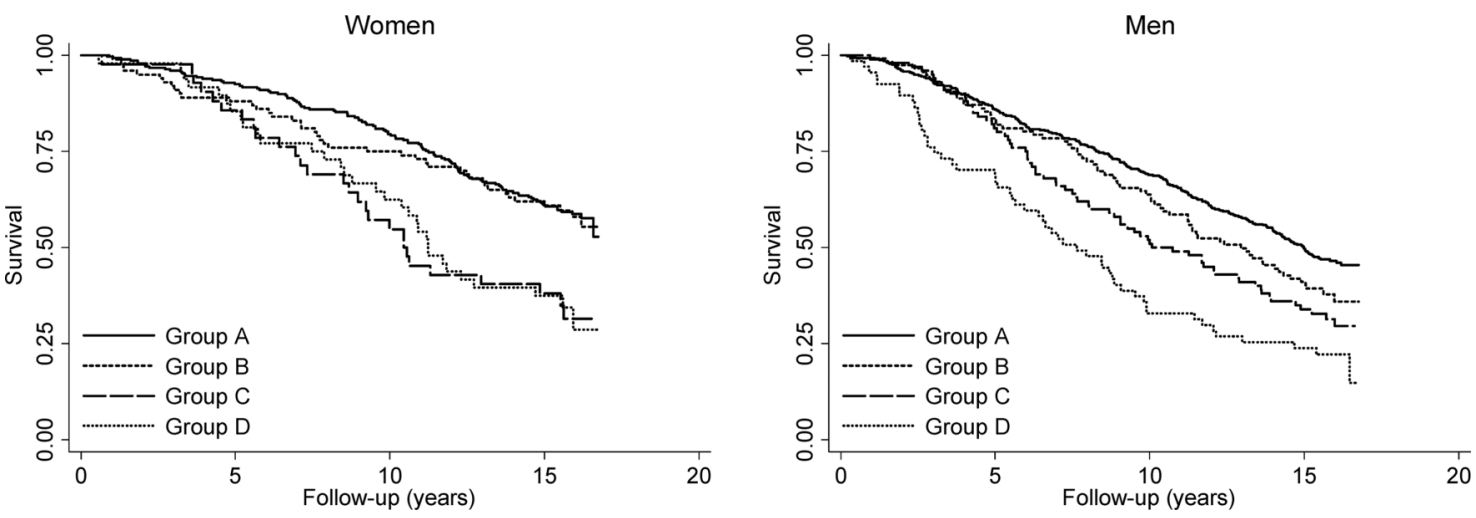

Figure 3 Kaplan-Meier curves according to $A B C D$ groups.

with mortality despite our findings. Studying over 10000 people from HUNT2, we recently found dyspnoea to be independently associated with mortality within four levels of prebronchodilator $\mathrm{ppFEV}_{1} \cdot{ }^{15}$ In order to add possible predictive value of symptom burden without losing predictive value from lung function, we suggest keeping all four spirometric GOLD grades in the combined COPD assessment in the next revision of the GOLD strategy document.

In contrast to the current study, Lange $e t a l^{5}$ found poorer survival in group $\mathrm{B}$ compared to group $\mathrm{C}$ in people with prebronchodilator COPD from the general population of Denmark, and they suggested CVD or cancer as possible explanations. Since most analyses were unadjusted, their results may have been biased by confounding factors. In addition, the average follow-up was 4.3 years, and it is possible that the associations will change with longer follow-up. In a pooled analysis of 11 COPD cohorts, Soriano et $a l^{6}$ found no difference between post-bronchodilator spirometric GOLD grades and ABCD groups in predicting mortality during almost 16000 person-years. Neither Lange et al $l^{5}$ nor Soriano et $a l^{6}$ performed sex specific analyses. In the current study, group B consisted of $21 \%$ of the women and $16 \%$ of the men, while group C consisted of $9 \%$ of the women and $14 \%$ of the men. This different distribution between sexes may reflect that women tend to report symptoms more often than men. ${ }^{16} 17$

Table 3 Informativeness* of spirometric Global Initiative for Chronic Obstructive Lung Disease (GOLD) grades and ABCD groups related to all-cause mortality among participants with chronic obstructive pulmonary disease (COPD) in the HUNT2 Lung Study

\begin{tabular}{|c|c|c|c|c|c|c|}
\hline \multirow[b]{2}{*}{ COPD classification } & \multicolumn{3}{|c|}{ Women $(n=468) \dagger$} & \multicolumn{3}{|c|}{ Men $(n=736) \dagger$} \\
\hline & $\chi^{2}$ & $(\%)$ & $\mathrm{p}$ Value & $\chi^{2}$ & $(\%)$ & p Value \\
\hline GOLD grades & 62.53 & $(100)$ & $<0.001$ & 32.47 & $(100)$ & $<0.001$ \\
\hline$A B C D$ groups§ & 26.28 & $(42)$ & $<0.001$ & 13.03 & $(40)$ & 0.046 \\
\hline
\end{tabular}

*The Cox null model included age (as the time scale), smoking (never, former, current, unknown) and education $(<10, \geq 10$ years, unknown). The Cox alternative models included spirometric GOLD grades or ABCD groups in addition to all in the null model. The $\chi^{2}$ shows the difference in twice the log-likelihood between the null model and the alternative model. The most informative model has the highest value of $\chi^{2}$ and has been set to $100 \%$.

tPeople with missing data on dyspnoea were excluded so that the results from the spirometric GOLD grades and the ABCD groups could be compared.

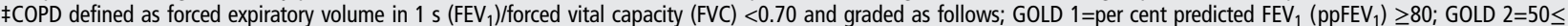

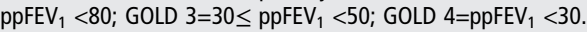

$\S A B C D$ groups defined as follows; $A=$ dyspnoea $\leq$ grade 1 , GOLD 1 or 2 , and $\leq 1$ exacerbation last 12 months; $B=$ dyspnoea $\geq$ grade 2 , GOLD 1 or 2 , and $\leq 1$ exacerbation last 12 months; $C=$ dyspnoea $\leq$ grade 1 , and GOLD 3 or 4 or $\geq 2$ exacerbations last 12 months; D=dyspnoea $\geq$ grade 2 , and GOLD 3 or 4 or $\geq 2$ exacerbations last 12 months. 


\section{Informativeness}

We observed that spirometric GOLD grades predicted mortality substantially better than ABCD groups, and this reflected the HRs and SMRs from the association analyses discussed above. Although symptom burden and exacerbation history may impact the choice of treatment and quality of life of people with COPD,${ }^{3}{ }^{4}$ our results indicate that the prognostic information given by the four spirometric GOLD grades should not be neglected when predicting mortality in people with COPD.

\section{Methodological considerations}

Since several analytical methods were used to disentangle our data, and they all led to similar interpretations of the results, we considered our findings robust. Our population-based study had a wide age span, and we had sufficient power to do sex specific analyses. ${ }^{16}$ Data on mortality were complete due to the unique personal identification number of all inhabitants of Norway, and there were no losses to follow-up. Since we included people based on lung function, both people with and without a physician diagnosis of COPD were included. Han et $a l^{29}$ recently studied the risk of future exacerbations according to the ABCD groups in 45-80 year-old people with COPD attending clinical centres in the USA. When using the mMRC dyspnoea scale to measure symptom burden, the distribution of participants differed considerably from our post-bronchodilator distribution and from the pre-bronchodilator distribution of the Danish epidemiological study, ${ }^{5}$ while the Spanish study of 11 COPD cohorts $^{6}$ had a more similar distribution to Han et al. ${ }^{29}$ This difference in distribution may reflect that patients with a physician diagnosis of COPD got their diagnosis because they experienced symptoms and therefore visited their doctor, although the inclusion criteria differed between these studies. ${ }^{5} 629$

A limitation of the current study was the lack of data on the mMRC dyspnoea scale ${ }^{12}$ or the CAT. ${ }^{13}$ However, our dyspnoea cut-off question was not very different from the mMRC dyspnoea scale grade 2 question. ${ }^{12}$ Since using alternate measures of dyspnoea or health status did not alter our findings and since the association with mortality seemed to be mostly related to lung function, we assume that using the mMRC dyspnoea scale or the CAT in generating the ABCD groups would not change our findings. Future studies on the association between ABCD groups and mortality using different cut-offs of the mMRC dyspnoea scale, ${ }^{12}$ the $\mathrm{CAT}^{13}{ }^{30}$ or other measures of symptom burden in generating the ABCD groups are needed. Further, $22 \%$ of our participants had missing data on the dyspnoea scale. However, it is unlikely that this has biased our results since using alternate measures of dyspnoea or health status with little or no missing data did not materially change our results. In addition, we have previously shown that baseline characteristics did not differ materially between people with and without data on the dyspnoea scale. ${ }^{15}$

\section{CONCLUSIONS}

Spirometric GOLD grades predicted mortality better than the new ABCD groups. In contrast to spirometric GOLD grades where mortality increased with higher grade, there were only minor differences in mortality between groups $\mathrm{A}$ and $\mathrm{B}$, and between groups $\mathrm{C}$ and $\mathrm{D}$. Our study supports the use of spirometric GOLD grades over the use of the new ABCD groups for predicting mortality.

Acknowledgements The second survey of the Nord-Trøndelag Health Study 1995-1997 (HUNT2) was a collaboration between HUNT Research Centre (Faculty of
Medicine, Norwegian University of Science and Technology), Nord-Trøndelag County Council, Central Norway Health Authority and the Norwegian Institute of Public Health.

Contributors $\mathrm{LL}$ and $\mathrm{AL}$ planned the study and are guarantors of this paper. $\mathrm{LL}$ analysed the data and wrote the paper. BMB and TILN participated in the data analyses. All authors interpreted the results and revised the paper. As project leader for the HUNT2 Lung Study, AL was responsible for planning, data collection and quality assurance of data in the Lung Study.

Funding This project was financially supported by the Norwegian ExtraFoundation for Health and Rehabilitation through EXTRA funds (project 2007/2/0214), the Liaison Committee between the Central Norway Regional Health Authority and the Norwegian University of Science and Technology (project 46041600), and the Leif Richard Erichsen and wife Maren Hertzberg Erichsen's fund for Norwegian medical research. The HUNT2 Lung Study received funding without obligation from AstraZeneca. None of the funding sources were involved in any aspect of designing or conducting the study, analysing data, interpreting results or writing the paper.

Competing interests LL presented a published paper for GlaxoSmithKline in 2012.

Ethics approval The Regional Committee for Medical Research Ethics (Central Norway).

Provenance and peer review Not commissioned; internally peer reviewed.

\section{REFERENCES}

1 World Health Organization, 2012. http://www.who.int/en/ (accessed 26 Nov 2012).

2 Mathers $C D$, Loncar D. Projections of global mortality and burden of disease from 2002 to 2030. PloS Med 2006;3:e442.

3 Vestbo J, Hurd SS, Agusti AG, et al. Global strategy for the diagnosis, management, and prevention of chronic obstructive pulmonary disease: GOLD executive summary. Am J Respir Crit Care Med 2013;187:347-65.

4 Global Initiative for Chronic Obstructive Lung Disease. Global Strategy for Diagnosis, Management, and Prevention of COPD, 2013. http://www.goldcopd.org (accessed 4 Feb 2013)

5 Lange P, Marott JL, Vestbo J, et al. Prediction of the clinical course of chronic obstructive pulmonary disease, using the new GOLD classification: a study of the general population. Am J Respir Crit Care Med 2012;186:975-81.

6 Soriano JB, Alfageme I, Almagro P, et al. Distribution and prognostic validity of the new GOLD grading classification. Chest 2013;143:694-702.

7 Krokstad S, Langhammer A, Hveem K, et al. Cohort profile: the HUNT Study, Norway. Int J Epidemiol. Published Online First: 9 August 2012. doi:10.1093/ije/dys095

8 Leivseth L, Nilsen TI, Mai XM, et al. Lung function and anxiety in association with dyspnoea: the HUNT study. Respir Med 2012;106:1148-57.

9 Langhammer A, Johnsen R, Gulsvik A, et al. Forced spirometry reference values for Norwegian adults: the Bronchial Obstruction in Nord-Trøndelag Study. Eur Respir J 2001;18:770-9.

10 Langhammer A. Respiratory symptoms, lung function, and bone mineral density in a comprehensive population survey: The Nord-Trøndelag Health Study 1995-97, The Bronchial Obstruction in Nord-Trøndelag Study [PhD Thesis]. Norwegian University of Science and Technology, 2003.

11 American Thoracic Society. Standardization of spirometry, 1994 update. Am J Respir Crit Care Med 1995:152:1107-36.

12 Mahler DA, Wells CK. Evaluation of clinical methods for rating dyspnea. Chest 1988;93:580-6

13 Jones PW, Harding G, Berry P, et al. Development and first validation of the COPD Assessment Test. Eur Respir J 2009;34:648-54.

14 Brogger JC, Bakke PS, Gulsvik A. Comparison of respiratory symptoms questionnaires. Int J Tuberc Lung Dis 2000;4:83-90.

15 Leivseth L, Nilsen TIL, Mai XM, et al. Lung function and respiratory symptoms in association with mortality: the HUNT Study. COPD Published Online First: 2013 (In press) doi:10.3109/15412555.2013.781578

16 Becklake MR, Kauffmann F. Gender differences in airway behaviour over the human life span. Thorax 1999;54:1119-38.

17 Langhammer A, Johnsen R, Holmen J, et al. Cigarette smoking gives more respiratory symptoms among women than among men. The Nord-Trøndelag Health Study (HUNT). J Epidemiol Community Health 2000;54:917-22.

18 Statistics Norway 2012. http://www.ssb.no/emner/02/02/10/dode/ tab-2012-04-19-02.html (accessed 17 Oct 2012).

19 Korn EL, Graubard BI, Midthune D. Time-to-event analysis of longitudinal follow-up of a survey: choice of the time-scale. Am J Epidemiol 1997;145:72-80.

20 Hernán MA, Robins JM. Causal Inference, 2012. http://www.hsph.harvard.edu/ faculty/miguel-hernan/files/hernanrobins_v1.10.19.pdf (accessed 11 Dec 2012).

21 Rothman KJ, Greenland S, Lash TL. Modern epidemiology. 3rd edn. Philadelphia: Lippincott Williams \& Wilkins, 2008.

22 Peto $\mathrm{R}$, Pike MC, Armitage $\mathrm{P}$, et al. Design and analysis of randomized clinical trials requiring prolonged observation of each patient. II. analysis and examples. $\mathrm{Br} J$ Cancer 1977:35:1-39. 
23 Lewington S, Clarke R, Qizilbash N, et al. Age-specific relevance of usual blood pressure to vascular mortality: a meta-analysis of individual data for one million adults in 61 prospective studies. Lancet 2002;360:1903-13.

24 Lewington S, Whitlock G, Clarke R, et al. Blood cholesterol and vascular mortality by age, sex, and blood pressure: a meta-analysis of individual data from 61 prospective studies with 55,000 vascular deaths. Lancet 2007;370:1829-39.

25 Morkedal B, Romundstad PR, Vatten LJ. Informativeness of indices of blood pressure, obesity and serum lipids in relation to ischaemic heart disease mortality: the HUNT-II study. Eur J Epidemiol 2011:26:457-61.

26 Mannino DM, Diaz-Guzman E, Buist S. Pre- and post-bronchodilator lung function as predictors of mortality in the Lung Health Study. Respir Res 2011:12:136.
27 Mannino DM, Doherty DE, Sonia Buist A. Global Initiative on Obstructive Lung Disease (GOLD) classification of lung disease and mortality: findings from the Atherosclerosis Risk in Communities (ARIC) study. Respir Med 2006;100:115-22.

28 Ekberg-Aronsson M, Pehrsson K, Nilsson JA, et al. Mortality in GOLD stages of COPD and its dependence on symptoms of chronic bronchitis. Respir Res 2005;6:98.

29 Han MK, Muellerova H, Curran-Everett D, et al. GOLD 2011 disease severity classification in COPDGene: a prospective cohort study. Lancet Respir Med 2013;1:43-50

30 Jones $\mathrm{P}$, Adamek L, Nadeau G, et al. Comparisons of health status scores with MRC grades in a primary care COPD population: implications for the new GOLD 2011 classification. Eur Respir J. Published Online First: 20 December 2012. doi:10.1183/09031936.00125612 